\title{
The Stalled Revolution of Contraception
}

\author{
H. PETER TARNESBY* \\ Sackler School of Medicine, Tel-Aviv University, Tel-Aviv, Israel
}

(Received 16 November 1998)

Keywords: Population grith, Population balance

The revolution of contraception began precisely on the $15 / 10 / 1951$. That was the day when, in the laboratory of the Syntex Corporation in Mexico City, Djerassi et al. [1] succeeded in synthesizing Norenthindrone (Fig. 1), an orally active progestagen with an activity 8 times greater than naturally occurring progesterone, and this was soon followed by their synthesis of norethisterone or NET. This laid the foundation of the era of steroidal control of human fertility by combining a synthetic oestrogen with a newly developed progestagen, viz. Mestranol with Norethindrone, resulting in suppression of ovulation. A woman taking this combined pill simply stopped having monthly periods, but she could be stimulated to have vaginal withdrawal bleeding by omitting to take this pill for a few days at the end of every month.

It took nine years for the Food and Drug Administration Authority to approve the first contraceptive pill in the US for general use in the year 1960, which meant the practical dawn of the revolution.
The acceptance of the pill was fueled by the simultaneous birth of the modern feminist movement, which demanded that women must be in control of their own bodies and especially their own fertility. Male dominance of fertility control was considered objectionable. Within 2 years 1.2 million women used it in the US and within 10 years nearly 10 million American women had accepted the pill as the most desirable method of birth control.

The dosages of the progestational and oestrogenic contents in the earliest pills were initially rather high, in order to avoid greater failure rates and to promote acceptance. Subsequent developments aimed to reduce these dosages over the next several years, until today we have a large choice of low dosage pills and so-called mini-pills which are devoid of any oestrogen. The reason was that enthusiasm began to be overshadowed by fears that the prolonged use of artificial hormones could harm healthy women. The FDA tested the pill for some nine years before approval, but the need to use it throughout the fertile years seemed to extend over

* Founder of the Tarnesby-Tarnowski Chair of Family Planning and Fertility Regulation. 


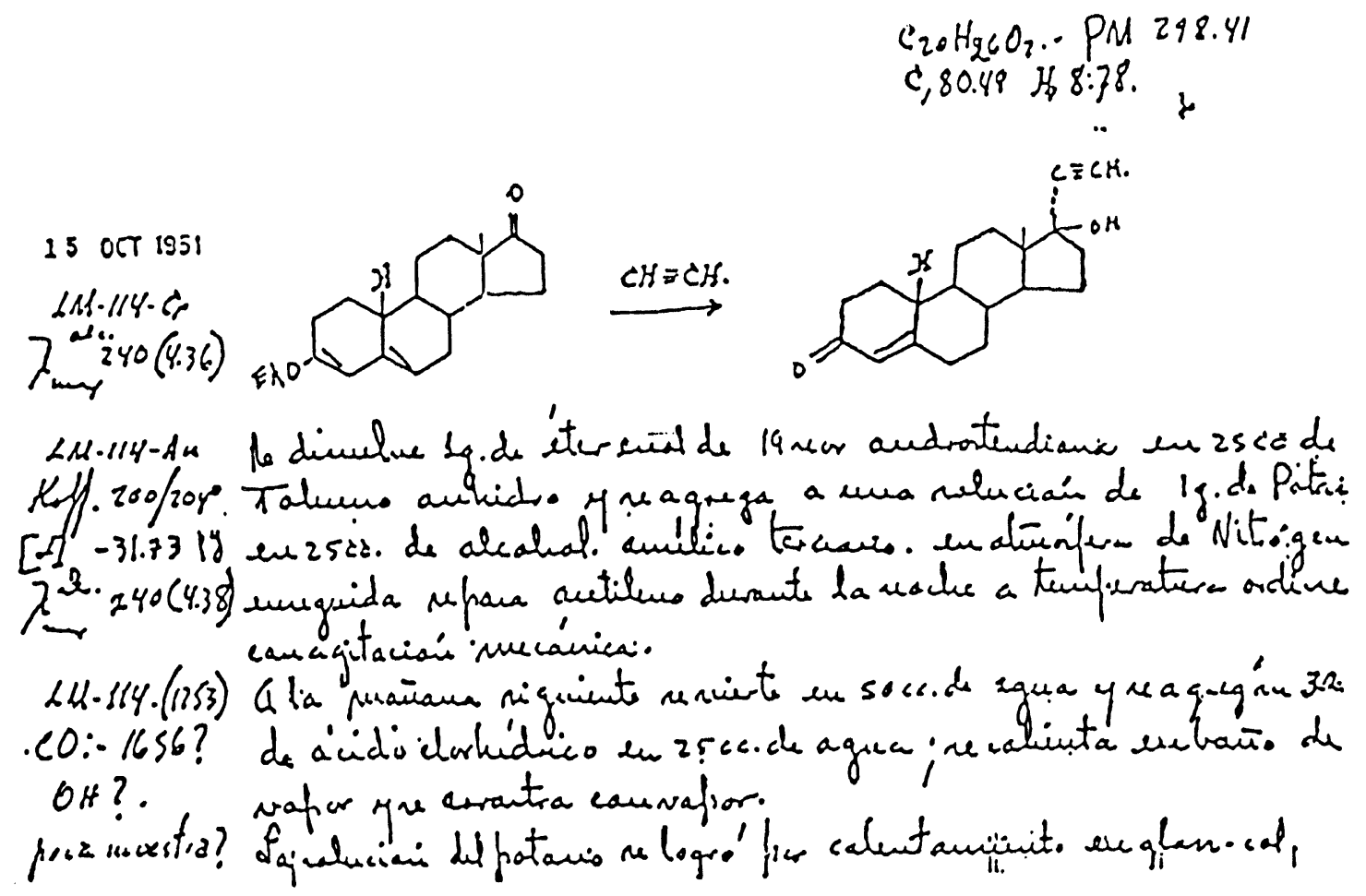

FIGURE 1 The final step in the original synthesis of norethindrone. Facsimile of the record of October 15, 1951, from Djerassi's laboratory where this synthesis was accomplished. The text describes the overnight (left-hand formula) reaction between enolether of androstenedione and various reagents under continuous mechanical agitation at room temperature. The text then outlines the steps to be taken the next day that are expected to result in synthesis of norethindrone (right-hand formula). (Courtesy of Syntex S.A., Mexico.)

some 30 years, from age 15 to 45 . While the first pills contained considerably more than $50 \mu \mathrm{g}$ of oestrogen, later ones only $25 \mu \mathrm{g}$ and the so-called mini-pills no oestrogen at all, the answers to the question of possible harm to health were not always completely reassuring.

There is an increased risk of cardio-vascular complications, venous thrombosis, varicose veins etc. - particularly in heavy smokers over the age of 35. There is an unconfirmed suspicion that there might be an increased risk of breast cancer, although extensive studies have so far failed to show convincing evidence and are not likely to be available for another 5 years or so. Cancer of the cervix of the uterus as well as certain adenocarcinomata do show a slight increase in users of the pill, whereas endometrial cancer may actually occur less often with them, as does ovarian cancer. The risk of liver cancer, though rare, does seem to increase slightly.

There are a whole lot of (Tables I and II) less serious side effects - such as putting on weight or an increased tendency to skin pigmentation of the face or chloasma. All of these side effects are constantly discussed in the media. Women's magazines, newspaper articles, radio and TV discussion tend to enlarge suspicions and fear of the consequences of the pill. The result has been a gradual reduction of pill-using women (Fig. 2 and Table III) from a high of 13 million in the US to about 8 million, or some $26 \%$ of married women to about $13 \%$ today [2]. The pattern of contraceptives used in 1987 and in 1988 is shown in Table IV and Fig. 3. There are about 60 million women aged 15-44 in the US. In 1960 when the pill was first used the teenage pregnancy rate of 15-19 years old girls in the US 
TABLE I Hormonal side effects of hormonal contraceptives

\begin{tabular}{|c|c|c|c|}
\hline Estrogen excess & Progestin excess & Estrogen deficiency & Progestin deficiency \\
\hline Nauses, vomiting & Fatigue, depression & Irritability, nervousness & $\begin{array}{l}\text { Late breakthrough bleeding } \\
\text { and spotting }\end{array}$ \\
\hline Edema, bloating & Acne, oily skin, hirsutism & Hot flashes, motor symptoms & $\begin{array}{l}\text { Heavy menstrual flow } \\
\text { and clots }\end{array}$ \\
\hline Cyclic weight gain & Alopecia & Early midcycle spotting & $\begin{array}{l}\text { Delayed onset of menses, } \\
\text { weight loss, dysmenorrhea }\end{array}$ \\
\hline Dysmenorrhea uterine cramps & Increased appetite & $\begin{array}{l}\text { Decreased amount of } \\
\text { early menstrual flow }\end{array}$ & \\
\hline \multirow{2}{*}{$\begin{array}{l}\text { Breast tenderness increased } \\
\text { breast size, vascular headaches }\end{array}$} & Shortened menses & No withdrawal bleeding & \\
\hline & Decreased libido & $\begin{array}{l}\text { Dry vaginal mucosa, } \\
\text { atrophic vaginitis }\end{array}$ & \\
\hline Chloasma & $\begin{array}{l}\text { Headache between } \\
\text { pill packages }\end{array}$ & Headaches & \\
\hline Lactation suppression & Dilated leg veins & Depression & \\
\hline Irritability, depression & Cholestatic jaundice & & \\
\hline
\end{tabular}

Note: Reprinted with permission from Sanfilippo, J.S. Adolescents and oral contraceptives. Intl. J. Fertil. 1991; 36(2): 65-79.

TABLE II Adolescents' concerns about birth control pills

\begin{tabular}{lc}
\hline Concern & Percent \\
\hline Weight gain & 45 \\
Interaction with cigarettes & 19 \\
Blood clots & 13 \\
Cancer & 12 \\
Blood pressure & 5 \\
Fertility & 5 \\
Birth defects & 4 \\
\hline
\end{tabular}

Note: Reproduced with permission from Emans, S.J. et al. Adolescents compliance with the use of oral contraceptives. JAMA 1987; 257.

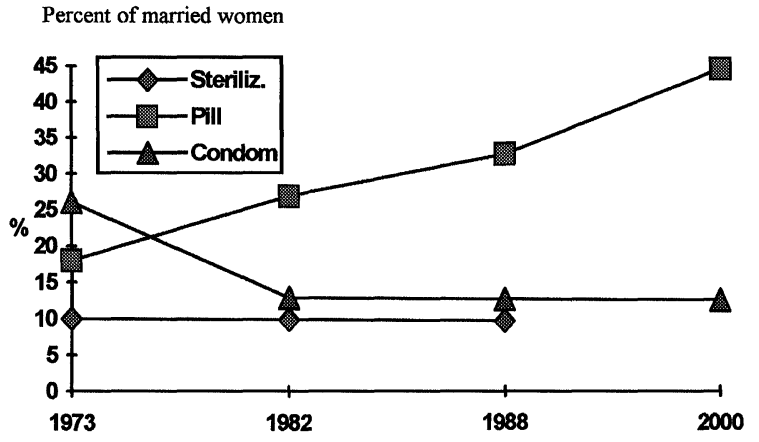

FIGURE 2 Percent of married couples (wives 15-44) using sterilization, pill, condom U.S. 1973 1988. (Reprinted with permission from Mosher and Pratt.)
TABLE III Worldwide prevalence* of specific contraceptive methods in 1983 and 1987

\begin{tabular}{lcr}
\hline Method & 1983 & 1987 \\
\hline Female sterilization & 28 & 29 \\
Male sterilization & 10 & 8 \\
Intrauterine device & 19 & 20 \\
Oral contraceptives & 15 & 14 \\
Injectable contraceptives & 1 & 2 \\
Condom & 10 & 9 \\
Withdrawal & 8 & 8 \\
Rhythm & 7 & 7 \\
Barrier methods & 2 & 1 \\
Other methods & 2 & 2 \\
\hline
\end{tabular}

U.N. Pop. Div. 1991 Percentage of users.

*WHO Statistics Quarterly, 47(1): 1994.

TABLE IV Contraceptives used worldwide

\begin{tabular}{lc}
\hline Voluntary female sterilization & $26 \%$ \\
Intrauterine devices (IUDs) & $19 \%$ \\
Oral contraceptives & $15 \%$ \\
Voluntary male sterilization & $10 \%$ \\
Condoms & $10 \%$ \\
Withdrawal & $8 \%$ \\
Natural family planning methods & $7 \%$ \\
Vaginal barrier methods & $2 \%$ \\
Injectable contraceptives & $1 \%$ \\
Other methods & $2 \%$ \\
\hline
\end{tabular}

Note: The number of contraceptive users worldwide was estimated to be 460 million in 1987 , or approximately $51 \%$ of couples exposed to the risk of pregnancy. 

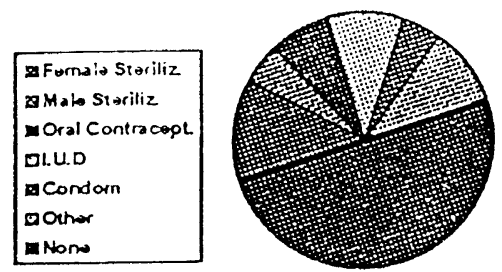

WORLD
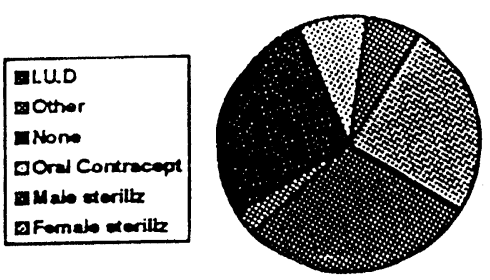

EAST AFRICA
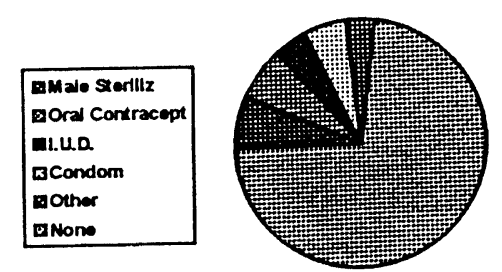

DEVELOPING COUNTRIES

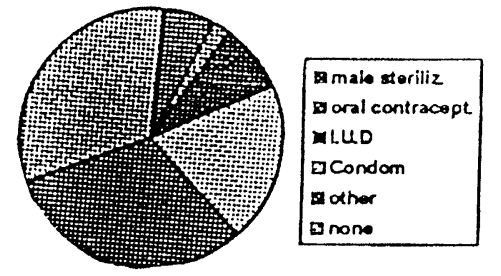

DEVELOPED COUNTRIES

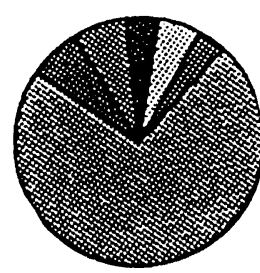

axilo storliz

intua

acondom

Dinone

SOUTH ASIA

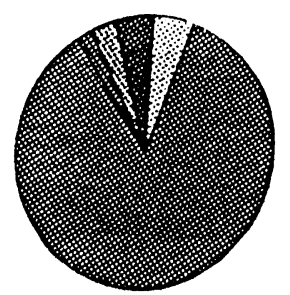

\begin{tabular}{|l|}
\hline Econdom \\
Eli.u. \\
Woral contracept \\
Dother \\
Dnone \\
\hline
\end{tabular}

AFRICA

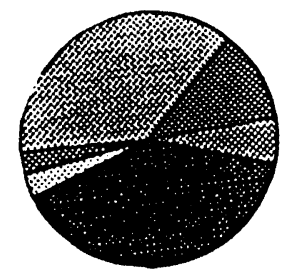

ande Sterillix

goral Contracept

al.u.

घCondom

Eoriner

anone

Dromalo Storillz

\section{LATIN AMERICA}

FIGURE 3 Patterns of contraceptive use in different regions.

was 7.9 per 1000 . In 1968 , after 8 years of pill availability it had risen to 23.4 and has risen steadily ever since. In 1979 it was 59.9 per 1000 and in $199262 / 1$ per 1000 girls. The revolution of sexual morality - or immorality had outweighted the contraceptive revolution three fold (Table V and Fig. 4).

About four years after the introduction of the pill, the IUD, or intra-uterine device, was approved
TABLE V Births to unmarried mothers percentages for the United States

\begin{tabular}{cccc}
\hline & All races $(\%)$ & Whites $(\%)$ & Blacks $(\%)$ \\
\hline 1970 & 10.7 & 5.6 & 37.5 \\
1975 & 14.3 & 7.3 & 46.8 \\
1980 & 17.8 & 10.2 & 55.5 \\
1985 & 22.0 & 14.5 & 60.1 \\
1990 & 28.0 & 20.1 & 65.2 \\
1991 & 29.5 & 21.8 & 67.9 \\
\hline
\end{tabular}

Note: Senator Moynihan, D.P. 1991 Natal Statistics. 
BIRTHS AND ABORTIONS/1000

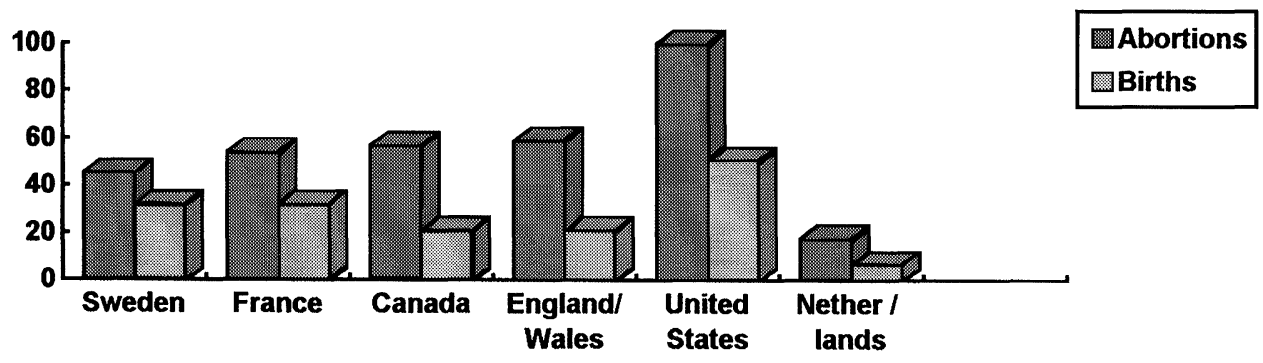

FIGURE 4 Pregnancy and abortion rates for teenagers aged 15-19 years by country (1980-1981). Adapted and reproduced with permission from Jones, E.F., Darroch-Forrest, J., Goldman, N. et al. Teen pregnancy in developed countries: determinants and policy. Fam Plan perspect 1985; 17(2): 53 63.

by the FDA. It promised to be an alternative, reliable, long-lasting and discreet device, a preventative, which could be fitted by a doctor well in advance of expected coitus and remain in situ for more than a year before being changed and renewed. True, the IUD was not really suitable for very young women owing to their narrow cervical canal and the small size of the uterus, nor was it ideal for those multi-parous women whose cervix was very lax and who might expel the device, perhaps without noticing it. Also there was the suspicion that inflammatory reactions might develop, leading to permanent infertility even after the IUD was removed. Indeed disaster struck in that the Dalkon Shield IUD demonstrated all of these complications and this resulted in massive litigation against the manufacturers, including a class action suit by literally thousands of women leading to eventual bankruptcy of one of the leading American pharmaceutical corporations in 1974 (A.H. Robins \& Co. Thirty-six women had septic spontaneous abortions; 195,000 sued the company, resulting in a Trust of US $\$ 2.47$ billion being set up).

Although subsequent models of IUD, such as the Copper- $\mathrm{T}$ as well as progesterone releasing types, were much safer, the fear of harmful results persisted not only among potential users, but also among manufacturers. This was dramatically reinforced in 1986 when a woman who had used the spermicidal cream Ortho-Gynol while she was already unknowingly pregnant had a baby with birth defects. A court in Georgia, USA, awarded her a judgement of more than 5 million dollars in compensation for the alleged harmful effects on her baby [3]. In fact that possibility is not consistent with current medical evidence. Then there was a woman in Minnesota. She developed a pelvic infection 12 days after being fitted with a Copper-T IUD. This left her infertile and she was awarded $\$ 8.75$ million against the manufacturers, G.D. Searle in 1977.

The litigenous attitude of American Society has increased enormously during the last 25 years and the awards and costs have been especially high in contraceptive cases. One reason is that women who avail themselves of contraceptives are not generally patients who are ill, but young and healthy women whom the courts wish to protect from any apparently unnecessary harm. This constitutes an almost unbearable burden on doctors and manufacturers of contraceptive products. It impedes progress in research for the future of contraceptive developments.

A second impediment is the extremely long period of testing on which the FDA insists before approval of a new contraceptive product, in general, more than 10 years and sometimes almost 20 years.

A third reason is the political influence of the US Congress supported by a hostile anti-abortion lobby as well as the media. The fanatical Pro-Life movement does not always restrict itself to fight abortion, but generally provides a poor image for 
sexually active women who wish to control their fertility.

Ten years after the pill became available there were nine major pharmaceutical companies in the US and four elsewhere, i.e. thirteen in all, who were actively engaged in research and development of contraceptives. They developed pills with remarkably reduced oestrogen contents as well as the mini-pill based on progesterone only. They also developed injectable hormones such as Depo Provero as well as subdermal hormonal implants, i.e. Norplant. These are basically new ways for women to receive ovulation suppressing hormones like those contained in birth control pills.

A few new gestagens have also been developed, such as Desogestrel, Gestodene and Norgestimate, but they distinguish themselves only slightly in their effect from the previous progestins.

The female condom, named Reality, has recently become available. It is a larger version of the male condom and if anything, less popular than that. All condoms have a limited appeal, because of the impaired sensation of the coital experience, the unromantic and messy application and the relatively high failure rate of $3.6-5$ per 100 women years [4]. This is in the face of vigorous governmental promotion on account of "safe sex" for the prevention of AIDS. In the meantime the thirteen firms conducting Research and Development in the contraceptive field have been reduced to four by 1987 and to one or two at the present time. Today none of the hormonal constituents of the contraceptive pills are manufactured in the US.

The most significant research achievement so far is the anti-progestin, Mefipristone (RU-486), which was developed in France by E. Baulieu in 1986 [5]. It has promptly been labeled the "French Death Pill" by anti-abortionists in the US, because it prevents implantation of the fertilized ovum in the endometrium, the inner lining of the womb, rather than the actual fertilization and can thus be classified as an "abortificiant". There is no current indication of FDA approval for it or any similar contragestion products.

What contraceptive methods hold out any reasonable hope for the future? Here is a priority list [6]:

1. An anti-fertility vaccine. Men or women could be vaccinated so that they remain infertile until a counter-vaccine restores their fertility. Research on this immunological method has been in progress since 1974 [7] but reliable results are still a distant hope expecially as concerns the reliability of the reversal.

2. A male contraceptive pill. The safety of pills for men is more difficult to ascertain than in women. Although research has been going on for some 20 years [6], progress is very slow. Trials with Gossypol, a derivative of the cotton plant, are proceeding in China, but the product is somewhat toxic and in about $10 \%$, infertility is irreversible [7].

3. Surgically reversible vasectomy with reliable reversible results. At present such reversal can only be achieved by means of expensive microsurgery [8].

4. "Once a month pill" allowing a woman to take only 12 pills a year instead of 250 or more to induce mense, but only if otherwise unprotected intercourse has taken place. Such a pill can also be termed "Morning after Pill" since it is taken post-coitally, the woman not knowing whether she carries a fertilized ovum or not. We already have the anti-progestin Mefipristone or RU-486, developed in France eight years ago. However, it is strictly an early abortion inducer and as such not acceptable to many. Also it disturbs subsequent menstrual cycles. Similar, improved anti-progestins could be developed given time and money - about 17 years and 150 million dollars!

5. An anti-viral spermicide which can be used in the form of an intravaginal pessary, foam or cream which would have the advantage of protecting also against AIDS as well as against pregnancy. No reliable product of this kind is currently available or likely to be soon.

6. Impregnated or coated condoms with antiviral and spermicidal functions.

So far this is a distant development, which carries with it the general objections 
associated with condoms. Nonetheless there would be a useful place for them in our contraceptive armamentarium. There are already several patents pending for condoms of this sort [9] but clinical trials are lagging.

7. A reliable ovulation predictor. To enable couples wishing to practice the natural rhythm method to detect more precisely the time of ovulation [4]. The present failure rates are still much too high, viz. $15.5 \%$ per 100 women years.

8. Improved barrier devices (caps, diaphragms, sponges) with anti-viral and spermicidal impregnations.

9. Surgically simple reversible female sterilization, which is inexpensive and reliable.

10. Temporary reversible sterilization in both men and women by inserting plugs in the fallopian tubes or vas deferens with controlled and reliable removal techniques. Studies have been in progress for several years, but the goal of complete reliability is still distant, especially regarding results after removal of the devices. What can be said is that the realization of some of the developments would indeed constitute a revival of the stalled revolution of contraception.

At the beginning of my life (in 1921) there were 1.8 billion people in this world. When I reached my 50 th birthday there were about 5 billion and now we are approaching the 6 billion mark. The projections for the 1st half of the next century vary from $8-12$ billion. The current rate of 3.3 children per woman might be reduced to 2.1 and lead to at least 11 billion people before leveling off at the end of the next century. If fertility could be reduced to 1.7 children per woman early next century we would peak at a population growth of 7.8 billion by 2050. But if fertility declines to no lower than 2.5 children per woman, the global population would exceed 19 billion by the end of next century and rise to 28 billion 50 years later [10]. Prof. Joel Cohen of Rockefeller University in New York City speaks of a world population of a possible 694 billion in the year 2150 ("How many people can the earth support?" December 1995, W.W. Norton $\&$ Co.). Since the resources of our planet are naturally finite and limited, we are heading for disaster and self-destruction. In the last decade food production from both land and sea has declined relative to population growth. The availability of water is already a constraint in some countries [11].

Today's world has 400 million fewer people that it would have had without Family Planning Programs (Population Council, 1990).

The 2.5 billion sexually active people on our planet engage in 100 million couplings per day. Nine hundred thousand - one million of these result in conceptions every day, half of these are unplanned (Fig. 5) and one quarter are unwanted, i.e. about 230,000 daily. Four hundred thousand live children are born every day, of which $20 \%$ will die before the age of 5 . The net increase in the world's population is 250,000 a day. All these figures are based on publications of the U.N. Population Fund [12]. There are also 150,000 abortions taking place each day, one third of them in developing countries without any medical supervision. One thousand four hundred women die every day of pregnancy related problems and of abortions, of these 500 die daily of abortion alone.

Why do 500 women have to die every day, mainly in developing nations? Because they are denied

\section{Per 1,000 women, 1987}

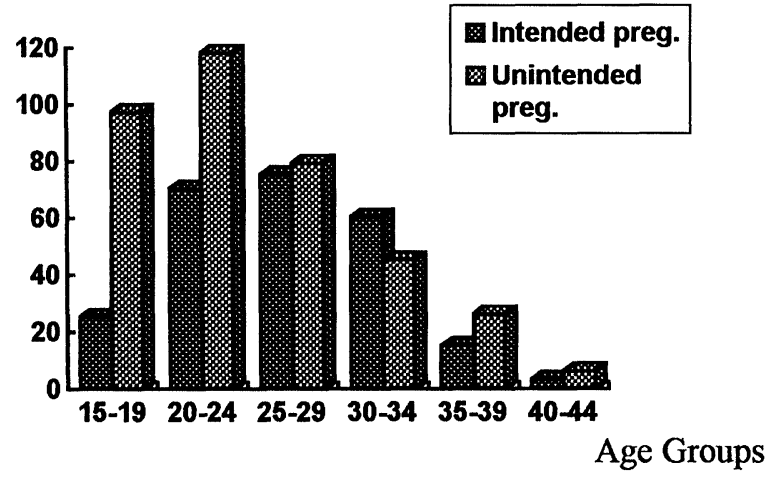

FIGURE 5 Most pregnancies in women under 24 or over 35 are unintended. (Reprinted with permission from Alan Guttmacher Institute.) 
freedom of reproductive choice - and the world hardly blinks an eye! What help can we offer them to prevent such dreadful suffering?

The contraceptive products available today would of course constitute a considerable potential help, if they were more widely and evenly available, and funded and supported by acceptable education in family planning. But we are still far from this goal. What do we have to offer in the way of really safe and effective contraception? The answer lies in the choices women are making in the United States at the present time. About $30 \%$ revert to female surgical sterilization, including some $12 \%$ of married women in the United States who are under the age of 30 and realizing that this is a generally irreversible procedure [8] except by means of expensive micro-surgery the success of which cannot be considered certain. If we add some $9 \%$ who chose male sterilization, or vasectomy, we arrive at $38 \%$ of all couples who nowadays opt for sterilization in the US more than those who chose the pill.

About $20 \%$ in the United States chose an IUD, whereas this is the most prevalent method of birth control in China where more than 35 million women use it [14]. About $13 \%$ use the pill in the US, $2 \%$ an injectable contraceptive and about $10 \%$ rely on the age-old condom which is of course, nowadays vigorously promoted because of its "safe sex" properties in reducing the danger of AIDS infection. About $8 \%$ practice coitus interruptus, $7 \%$ the rhythm method advocated by the Catholic Church and a few use barrier methods such as caps, diaphragms and spermicidal creams or pessaries [15].

More than 1/3 of unwanted pregnancies result in abortions, legal or illegal. The abortion rate is about $33 \%$ in the US - higher than in other developed countries. It is about $27 \%$ in Israel and $23 \%$ in the United Kingdom (Table VI). In Canada it is $17 \%$ [7]. When considering these awesome statistics a cry for better contraception can be heard with increasing urgency. Better contraception means more Research and Development in the field. But the contraceptive revolution has stalled, Research and Development has dried up. Research scientists have turned to other
TABLE VI Live births and abortions in Israel, USA and United Kingdom

\begin{tabular}{lcrc}
\hline & Israel 1992 & USA 1991 & United Kingdom 1991 \\
\hline Live births & 110144 & 4110000 & 792508 \\
Legal abortions & $30000^{*}$ & 1354000 & 184092 \\
$\%$ of live births & 27 & 33 & 23 \\
\hline
\end{tabular}

*Legal and illegal.

fields. There is stagnation in the range of choices and the quality of contraception. It has now become more fashionable to study alleviation of infertility rather than contraceptive control.

This is partially due to lack of money and encouragement from the United States and other government sources as well as from great private and corporate foundations, which have lost interest. Primary research, such as it is, has moved to Europe and Asia, despite the size of the American market.

What is the solution? Research, development and distribution are impossible without the active participation of the pharmaceutical industry.

Pharmaceutical corporations can only be enticed back if they receive active encouragement from governments. The direction lies in modifying the approval procedures i.e. shortening the approval times from the present 15-20 years in the United States. Also the patent laws would need to be amended to extend protection well beyond the required period of development until approval. In addition so-called no fault insurance programs should be introduced such as are being considered in the United States for the introduction of new vaccines to combat infections such as AIDS or malaria. These programs would indemnify vaccine or contraceptive providers against potential legal damages and costs, allowing the necessary insurance premiums to be added to the cost of the product. We are still far removed from such changes. The time is not yet ripe. The revolutionary and promising pill has resulted in a bitter pill - a term used by no other than its father Djerassi himself! Many more women will have to die of abortion, many more abortions will have to take place shaming the dignity of the human spirit. 
An astronomical increase of the number of unwanted babies will have to occur and a population explosion of nearly unbearable magnitude will have to engulf us before the bitter taste of this pill will eventually cause the next generation, or perhaps the one following it, to take the essential steps towards the salvation of mankind.

If the anti-abortion forces would have their way in effectively managing the prevention of all abortions, which in practice is inconceivable, then the actual addition to the daily increase of the world's population would increase from 250,000 to 400,000 or from annually 90-100 million to 140 million. The projected 8 billion people of the next century would swell to over 12 billion and the numbers at the end of the next century would increase to some 20 billion. Since contraception cannot at present provide for all the women who do and inevitably will have abortions, legally or illegally, morally or immorally, it is fair to say that abortions constitute an essential safety valve for humanity in distress. If we like it or not, nature in its wisdom has provided an albeit undesirable way out of the dilemma, at great cost in women's lives and human suffering. That sad state of affairs imposes on mankind an obligation at least temporarily to alleviate the situation, by providing for medically supervised and therefore safer abortions. It is essential to stop criminalizing and persecuting abortions, to provide more and better facilities for them with legal and social protection. However, we seem to do the very opposite. Under the lead of the US Pro-Life movement the pendulum has swung distinctly against abortions. Mine is of course not a call for more abortions, but a plea not to tamper with the safety valve until the time we have something better to offer, and in the meantime concentrate on saving women's lives and improve their condition. Instead of training doctors to be able to perform such operations safely many medical faculties have ceased to provide such training, many hospitals, particularly in the United States are cutting down on abortion facilities, those who provide them are often threatened. This happens not only in America, but increasingly in other countries. We are turning back the clock, we are driving abortion underground. Even if the statistics show a reduction in the number of abortions recently, especially in the US this is counterbalanced by illegal abortions which are less safe, leading to greater mortality and morbidity.

The revolution of contraception has stalled, the liberalization of abortion has stalled, the suffering of women and their families is increasing and we continue to over-populate our planet with little immediate hope for improvement in sight. Things have to get worse before they can get better. Let us hope that they will eventually get better and Tel-Aviv University which has established the first Chair in the world in Family Planning and Fertility Regulation will give a lead in providing solutions for these great problems threatening mankind.

\section{References}

[1] Djerassi, C., Miramontes, L. and Rosenkranz, G. J. Am. Chem. Soc. 1951; 73: 3540; American Chemical Society Meeting 1952; Abstract $18 \mathrm{~J}$.

[2] Forrest, D.D. and Fordyce, R.R. Fam. Plan. Perspect. 1982; 20(6): 112.

[3] Well, V. Ortho Pharmaceutical Co. 615 F. Suppl. 262 (N,D,GA 1985) aff'd 788 F. 2d \& 4Z(11th Cir 1986).

[4] Vessey, M., Lawless, M. and Yeates, D. Efficacy of different contraceptive methods. Lancet. 1982; 1: 841-2.

[5] Baulieu, E.E. RU-486 as an antiprogesterone steroid. J. Am. Med. Assoc. 1989; 1808-14.

[6] Djerassi, C. The bitter pill. Science 1989; 245: 356-61.

[7] Caspi, E. Contraception in the year 2000. TAU Inaugauration of the Tarnesby-Tarnowski Chair for Family Planning and Fertility Regulation, pp. 18-19 and p. 22.

[8] Sciarra, J.J. Zatuchni, G. and Speidel, J.J. Reversal of sterilization (Harper \& Row Hagerstown, MD 1977).

[9] United States patent 4,100,309. See also 3,860,672 and $3,939,049$.

[10] Population Reference Bureau. The UN long range population projections: What they tell us. Washington D.C. 1992.

[11] Population growth, resource consumption, and a sustainable world, Royal Society of London and US National Academy of Sciences, 1992.

[12] Meyers, N. Sen. Advixer U.N. Population Fund. Intern Herald Tribune. September 10-11, 1994, p. 4; and Report of the International Conference on Population and Development (Cairo 5-13 September 1994) United Nations publ. 1994.

[13] Cohn, Joel. How many people can the earth support? W.W. Norton \& Co. December1995.

[14] Bilian, X. Outlook 1989; 7(1): 2.

[15] U.N.Pop. Div. 1991. Worldwide prevalence of specific contraceptive methods. 


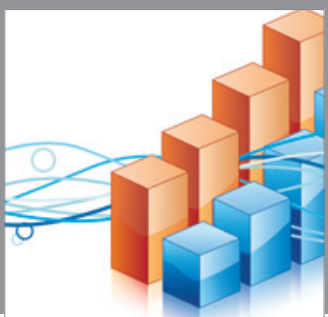

Advances in

Operations Research

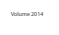

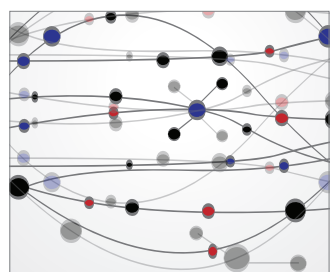

\section{The Scientific} World Journal
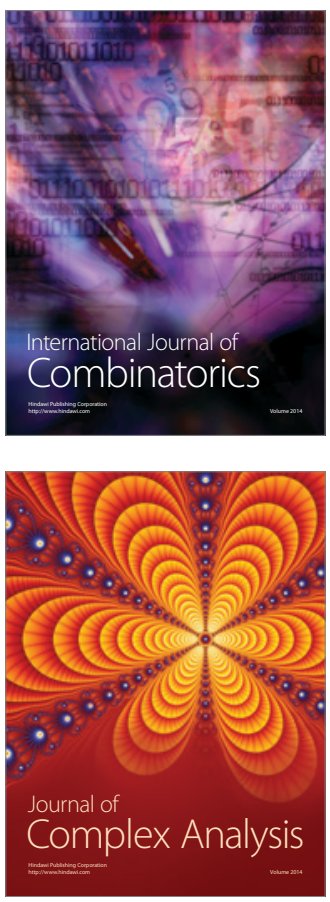

International Journal of

Mathematics and

Mathematical

Sciences
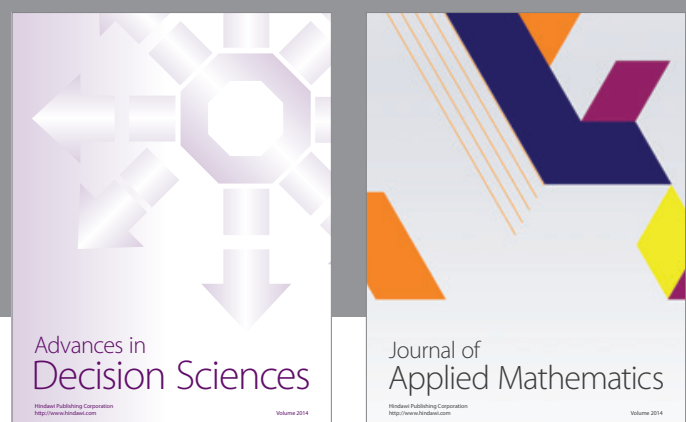

Journal of

Applied Mathematics
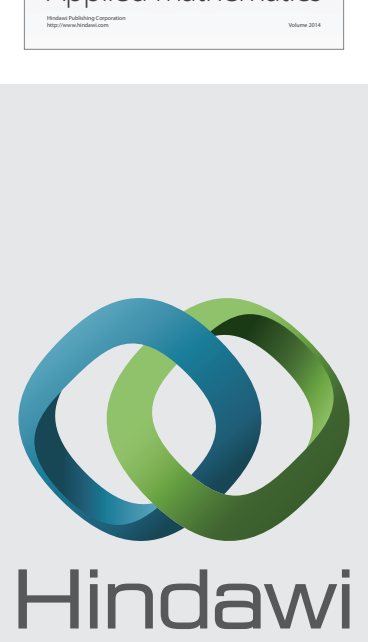

Submit your manuscripts at http://www.hindawi.com
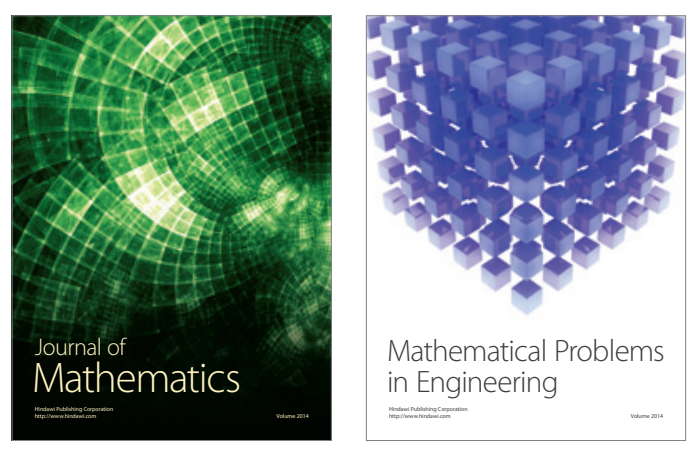

Mathematical Problems in Engineering
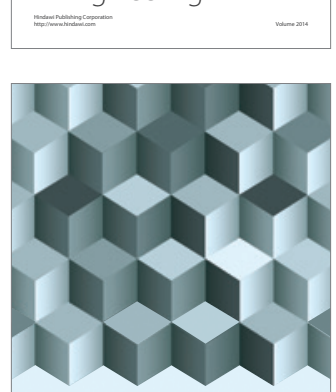

Journal of

Function Spaces
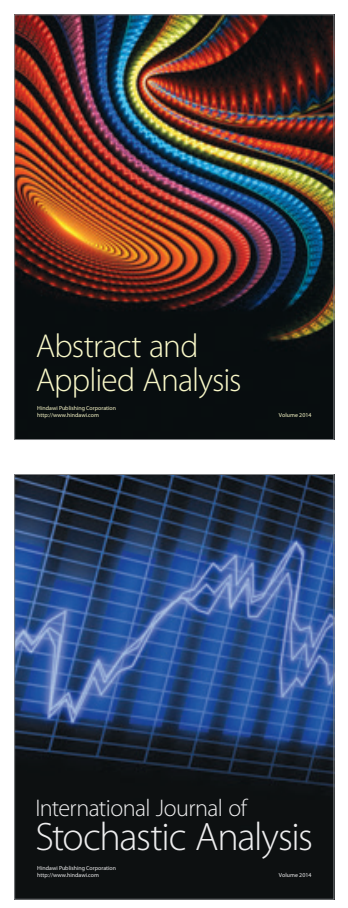

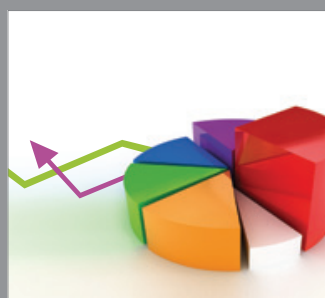

ournal of

Probability and Statistics

Promensencen
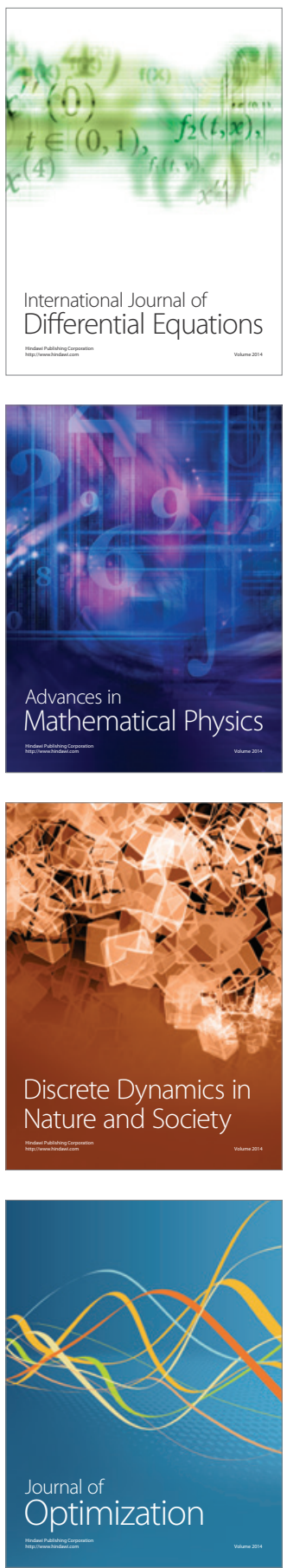